\title{
Nonlinear ultrasonic characterization of precipitation in 17-4PH stainless steel
}

\author{
Kathryn H. Matlack ${ }^{\mathrm{a}, *}$, Harrison A. Bradley ${ }^{\mathrm{b}}$, Sebastian Thiele ${ }^{\mathrm{c}}$, Jin-Yeon Kim ${ }^{\mathrm{c}}$, James J. Wall ${ }^{\mathrm{d}, \mathrm{b}}$, Hee Joon Jung ${ }^{\mathrm{e}}$, \\ Jianmin $\mathrm{Qu}^{\mathrm{f}}$, Laurence J. Jacobs ${ }^{\mathrm{b}, \mathrm{c}}$
}

\begin{abstract}
This research is part of a broader effort to develop a nondestructive evaluation technique to monitor radiation damage in reactor pressure vessel steels, the main contributor being copper-rich precipitates. In this work, $17-4 \mathrm{PH}$ stainless steel is thermally aged to study the effects of copper precipitates on the acoustic nonlinearity parameter. Nonlinear ultrasonic measurements using Rayleigh waves are performed on isothermally aged 17-4PH. Results showed a decrease in the acoustic nonlinearity parameter with increasing aging time, consistent with evidence of copper precipitation from hardness, thermo-electric power, transmission electron microscopy, and atom probe tomography measurements.
\end{abstract}

Keywords: Nonlinear ultrasonic methods, Thermal embrittlement, Precipitate hardening, Nonlinear Rayleigh waves

\section{Introduction}

Recent research has shown that the nonlinear ultrasonic technique of second harmonic generation (SHG) can detect radiation-induced microstructural changes in reac5 tor pressure vessel (RPV) steel samples [1,2]. These neutron irradiated samples are by nature extremely difficult to work with, since samples are radioactive, require experimentation and storage in either hot cell facilities or at least in shielding fixtures, contaminate experimental instrumen10 tation, and create radioactive waste. Therefore, it is of interest to develop a set of surrogate specimens that approximates some aspect of an irradiated RPV steel microstructure. A sample set such as this could help deconvolve influ- 40 ences of different microstructural features to the acoustic 15 nonlinearity parameter, $\beta$, since a surrogate sample set will only contain selected microstructural features present in radiation damage. A similar approach of utilizing surrogate material or model alloys (simple binary or ternary alloys) for investigating the microstructural changes from 20 radiation damage on steels has been widely used in the radiation damage community, e.g. $[3,4,5,6,7,8]$.

$17-4 \mathrm{PH}$ stainless steel has been identified as a possible surrogate material. This stainless steel is known to harden through the formation of copper precipitates dur25 ing thermal aging up to a peak aging time $[9,10,11$, $12,13]$, and the formation and growth of copper-rich precipitates in RPV steels are the most important contributor to radiation embrittlement [14]. The purpose of this

\footnotetext{
* Corresponding author

Email address: matlackk@ethz.ch (Kathryn H. Matlack)
}

paper is to characterize thermal aging of $17-4 \mathrm{PH}$ material with SHG measurements of $\beta$ using Rayleigh waves. Thermal aging of $17-4 \mathrm{PH}$ in this paper will focus on aging times below peak aging, since overaging causes a decrease in the hardness. These measurements are interpreted using the precipitate-pinned dislocation model [15], along with hardness measurements, thermo-electric power (TEP) measurements, transmission electron microscopy (TEM), and atom probe tomography (APT). These measurements and model provide insight into how precipitate parameters can be extracted from measurements of $\beta$.

\section{Background}

As an initially monochromatic ultrasonic wave propagates through a nonlinear material, higher harmonics are generated. These higher harmonics are caused by the distortion of the wave due to the nonlinear stress-strain relationship within the medium. The amplitude of the second harmonic wave can be related to that of the first harmonic through the acoustic nonlinearity parameter $\beta$ according to

$$
\beta=\frac{A_{2}}{A_{1}^{2}}\left(\frac{8}{\kappa^{2} x}\right)
$$

where $A_{1}$ and $A_{2}$ are the amplitudes of the first and second harmonic wave, respectively, $\kappa$ is the wavenumber, and $\mathrm{x}$ is the propagation distance. Considering that $\beta$ is proportional to the ratio $A_{2} / A_{1}^{2}$, a measure of the parameter can be obtained through a linear fit of a series of experimentally obtained first and second harmonic amplitudes. As $\beta$ is also dependent on propagation distance, the evaluation 
can be performed over a range of excitation amplitudes or 85 propagation distances. For this research, second harmonic generation of Rayleigh surface waves was measured over a range of propagation distances. However only electrical amplitudes are measured in this work, and the resulting calculation is limited to a relative measurement of nonlin- 90 earity $\beta^{\prime}$ given by

$$
\beta \propto \beta^{\prime}=\frac{A_{2}}{A_{1}^{2} x}
$$

Second harmonic generation measurements have been uti- ${ }^{95}$ lized in a wide variety of metallic materials, for example to characterize fatigue damage $[16,17,18,19,20]$, thermal aging $[21,15,22,23,24,25]$, creep damage [26, 27], and 45 radiation damage $[28,2]$. During thermal aging of metallic alloys, the magnitude of $\beta$ changes with the nucleation and ${ }^{100}$ growth of precipitate phases, and is specifically sensitive to the precipitate size (radius) and number density/volume fraction $[15,21]$. Changes in dislocation density will also change the magnitude of $\beta$ [29], which may or may not occur during thermal aging, depending on the material, ${ }^{10}$ thermal aging temperature and time, cooling rate, etc.

\section{Microstructural Changes in $17-4 \mathrm{PH}$}

$17-4 \mathrm{PH}$ stainless steel is a precipitate hardenable (hence the designation "PH") martensitic alloy. It is a "selfquenching" steel, meaning it transforms from austenite to martensite irrespective of the cooling rate. It has been shown that the martensitic transition begins at $160^{\circ} \mathrm{C}$ upon $_{115}$ cooling from above the austenitic temperature. Hardening in this material is caused by thermal aging, where the material is held at a temperature between about $400^{\circ} \mathrm{C}$ and $600^{\circ} \mathrm{C}$ for some time [30]. In these temperature ranges, copper has a low solubility, and so these atoms diffuse ${ }_{120}$ and form precipitates, which pin dislocations. Generally,

65 an increasing amount of coherent precipitates form in the material up to a peak aging time. After peak aging, these precipitates coarsen and become incoherent with the matrix, causing overaging and thus a decrease in hardness.

It has been reported that $17-4 \mathrm{PH}$ material in the solu-

70 tion annealed state (typically $1050^{\circ} \mathrm{C}$ for 1 hour followed by water quenching) exhibits a martensitic microstructure with a small percent of alpha-ferrite (reported to be $\sim 7 \%$ at room temperature in [9]). Microstructural analysis has shown no copper precipitates formed in the marten-

75 sitic phase of the solution annealed state. TEM analysis ${ }^{130}$ showed a high density of small, incoherent precipitates of fcc-copper in the alpha-ferrite phase, which remained unaffected by subsequent heat treatment [11]. Dislocation density in the martensite phase at room temperature has been so reported to be $4 \times 10^{15} / \mathrm{m}^{2}$, and about $1 \times 10^{15} / \mathrm{m}^{2}$ in the austenite phase; this dislocation density has been shown ${ }^{135}$ to remain constant up to about $500^{\circ} \mathrm{C}$ [9]. These dislocations are induced in the martensite and austenite phases during transformation due to the difference in density of the two phases such that regions of forming martensite cause deformation on the surrounding austenitic regions. Viswanathan et al. mention possible quenched-in vacancies should be present in the quenched microstructure as well, but the authors do not provide evidence of these vacancies [12].

Further heat treatment and tempering has been shown to produce copper-rich precipitates. In the standard "tempered" microstructure - after aging for 4 hours at $580^{\circ} \mathrm{C}$ - fine coherent bcc-copper precipitates were detected with bright-field TEM and three-dimensional atom probe analysis [11]. Quantitative values for the density and the size of these precipitates were not given. Heat treatment beyond this tempering has been shown to produce a high density of incoherent copper-rich precipitates, with a reported diameter of $3 \mathrm{~nm}$ after 100 hours of aging at $400^{\circ} \mathrm{C}$, and a diameter of $8 \mathrm{~nm}$ after 5000 hours of aging at $400^{\circ} \mathrm{C}$, along with other phases and precipitates alloyed with other elements [11].

Hsiao and co-authors [13] measured copper-rich elliptical precipitates with short and long axis dimensions of $15 \mathrm{~nm}$ and $25 \mathrm{~nm}$ in diameter, in a sample that was aged at $480^{\circ} \mathrm{C}$ for 1 hour after solution annealing and water quenching. The authors state that the precipitate is shown to be coherent from TEM bright field images since there is no large strain contrast, however FEG-TEM shows the precipitate has an fcc structure, indicating it is incoherent with the matrix.

Bhattacharya and co-authors [10] conducted magnetic Barkhausen noise measurements in aged 17-4PH. Corresponding X-ray diffraction measurements showed that samples in the quenched condition had a residual stress of $-248 \pm 20 \mathrm{MPa}$, and after aging for $1 \mathrm{~h}$ at $475^{\circ} \mathrm{C}$ this stress was reduced to $18 \pm 8 \mathrm{MPa}$.

Note that in addition to precipitates, dislocations also strongly contribute to nonlinearity. So, to investigate precipitation effects on the acoustic nonlinearity parameter using 17-4PH material, an aging temperature should be chosen such that the dislocation density remains constant over heat treatment. Previous work measured dislocation density changes in $17-4 \mathrm{PH}$ samples with neutron diffraction, showing dislocation density starts to decrease drastically around and above $500^{\circ} \mathrm{C}$, below which the dislocation density in the martensite phase remains roughly constant at $4 \times 10^{15} / \mathrm{m}^{2}[9]$.

\section{Specimen Preparation}

Bulk material of $17-4 \mathrm{PH}$ stainless steel, with composition shown in Table 1, was received as rectangular bars of dimensions $19 \mathrm{~mm}$ x $38 \mathrm{~mm}$ x $230 \mathrm{~mm}$. The material had an ultimate tensile strength of $1384 \mathrm{MPa}$ and a yield strength of approximately $1263 \mathrm{MPa}$. The as-received material was previously hot rolled and solution annealed at $1040^{\circ} \mathrm{C}$ for 6 hours, and then air cooled. The rectangular bar samples were left in the as-received geometry and used 
Table 1: Chemical composition of as-received 17-4PH stainless steel.

\begin{tabular}{ccccccc}
\hline $\mathrm{C}$ & $\mathrm{Cr}$ & $\mathrm{Cu}$ & $\mathrm{Ni}$ & $\mathrm{Mn}$ & $\mathrm{Si}$ & $\mathrm{Nb}$ \\
0.023 & 15.15 & 3.07 & 4.46 & 0.63 & 0.46 & 0.26 \\
\hline \hline $\mathrm{Mo}$ & $\mathrm{Co}$ & $\mathrm{N}$ & $\mathrm{P}$ & $\mathrm{S}$ & $\mathrm{Ti}$ & $\mathrm{Fe}$ \\
0.08 & 0.044 & 0.023 & 0.016 & 0.001 & 0.001 & remain. \\
\hline
\end{tabular}

for the nonlinear Rayleigh wave measurements. All speci140 mens were surface ground at low speed and with sufficient cooling to ensure smooth and parallel faces. After surface grinding, as well as after all heat treatments, samples were hand polished with 400 grit polish paper.

All samples received a solution annealing treatment of 145 holding at $1040^{\circ} \mathrm{C}$ for 6 hours then air cooled, i.e. the asreceived state (referred to herein as "AC" for "air cooled"). Some samples were isothermally aged for 0.1-6 hours at $400^{\circ} \mathrm{C}$. This aging temperature was selected to ensure dislocation density remained constant during the heat treatments while simultaneously forming copper precipitation. ${ }_{185}$ Then, some as-received samples were given a second solution annealing treatment at $1100^{\circ} \mathrm{C}$ for 2 hours in an uncontrolled atmosphere and then water quenched (referred to herein as "WQ" for "water quenched"). One WQ sample was then aged for 1 hour at $400^{\circ} \mathrm{C}$. The purpose of ${ }_{190}$ this second WQ sample set was to eliminate the formation of precipitates during the cooling stage of the solution anneal - since the air cooled sample slowly cooled through the temperature range where precipitates can form, it is possible that the purely AC samples already had some ${ }_{195}$ precipitates. Note that the water quenching could produce some quenched-in vacancies in the microstructure, that were likely not present in the AC samples.

The aging portions of all the treatments, conducted at $400^{\circ} \mathrm{C}$, were done in an uncontrolled atmosphere furnace, heated from room temperature at an average rate of $9^{\circ} \mathrm{C} / \mathrm{min}$. A thermocouple close to the surface of the samples was used to monitor the sample temperature. After the aging time was reached, samples were removed from

170 the furnace and air cooled to room temperature. A summary of the sample designations and aging conditions are ${ }_{205}$ given in Table 2.

\section{Material Characterizations}

\subsection{Hardness and TEP measurements}

210

Vickers hardness measurements and thermo-electric power measurements were made on all $17-4 \mathrm{PH}$ samples to assess the success of the heat treatments. The measured hardness for the aged 17-4PH samples is shown in Figure 1 [31]. These hardness measurements were made using a215 $2000 \mathrm{~g}$ force for 10 seconds. Results show an increase in hardness with increasing heat treatment time, as is expected for the aging temperature of $400^{\circ} \mathrm{C}$ and time up

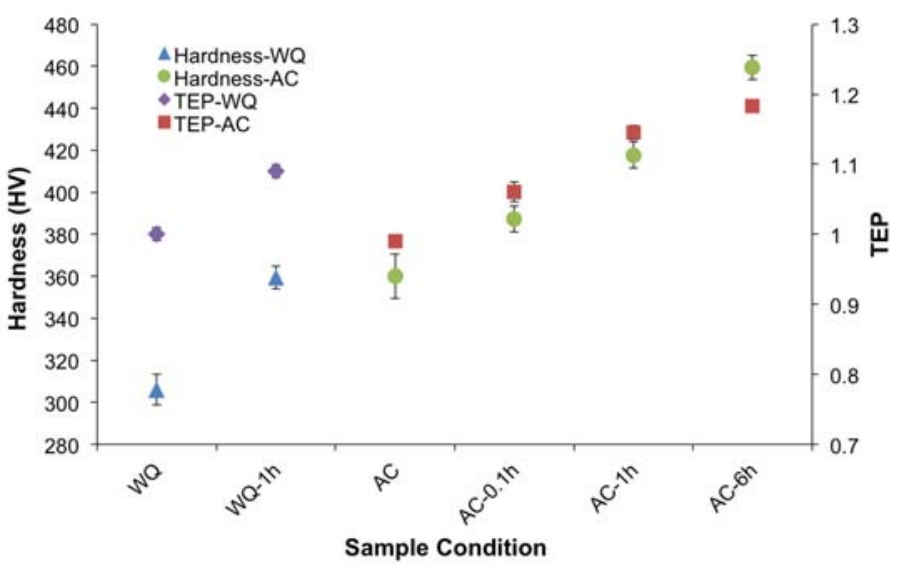

Figure 1: Measured Vickers hardness and thermo-electric power (TEP) for 17-4PH heat treated samples, in the water quenched and air cooled initial state.

to 6 hours [30]. These results indicate an increasing volume fraction of precipitates for increasing heat treatment times. The fact that the hardness of the air cooled sample is comparable to that of the WQ-1 sample suggests that some precipitates have already formed in the air-cooled as-is sample.

Thermo-electric power (TEP) results are shown in Figure 1 for all samples [31]. Results are normalized to the TEP value of the water quenched state. This normalization is done for reasons of readability, and no negative TEP values occurred. Results show an increase in TEP with increasing heat treatment time for both quenched and air cooled initial state samples. It is specifically pointed out that the TEP value for both the water quenched samples and the air cooled samples is the same. An increase in TEP corresponds to a decreasing amount of copper in the matrix material, indicating an increasing volume fraction of copper precipitates. Note that this likely means an increase in number density of copper precipitates, since precipitation is driven by an increasing number density in early stages of nucleation as found by Mirazdeh et al. [30].

\subsection{TEM Analysis}

TEM analysis was conducted at Pacific Northwest National Laboratory on the air-cooled $17-4 \mathrm{PH}$ samples, in efforts to characterize the size and number density of the precipitates. TEM samples were prepared using a focused ion beam.

However, the microstructure was so heavily dislocated and deformed that it was difficult to accurately view and analyze the precipitates. A TEM image of the air-cooled as-received (AC) condition is shown in Figure 2. There was little evidence of precipitation in this condition, and the images were dominated by contrast produced by a high density of dislocations in the grains. The high density of dislocations limited the ability to image any precipitation unless precipitates were relatively large (at least $2-4 \mathrm{~nm}$ in radius). 
Table 2: Sample designations and aging conditions for 17-4PH samples.

\begin{tabular}{cccc}
\hline $\begin{array}{c}\text { Sample } \\
\text { Name }\end{array}$ & $\begin{array}{c}\text { Solution } \\
\text { Anneal }\end{array}$ & $\begin{array}{c}\text { Cooling } \\
\text { type }\end{array}$ & $\begin{array}{c}\text { Aging Time } \\
\text { @ } 400^{\circ} \mathrm{C}\end{array}$ \\
\hline $\mathrm{WQ}$ & $1100^{\circ} \mathrm{C} / 2 \mathrm{~h}$ & water quenched & - \\
$\mathrm{WQ}-1$ & $1100^{\circ} \mathrm{C} / 2 \mathrm{~h}$ & water quenched & $1 \mathrm{~h}$ \\
$\mathrm{AC}$ & $1040^{\circ} \mathrm{C} / 6 \mathrm{~h}$ & air cooled & - \\
$\mathrm{AC}-0.1$ & $1040^{\circ} \mathrm{C} / 6 \mathrm{~h}$ & air cooled & $0.1 \mathrm{~h}$ \\
$\mathrm{AC}-1$ & $1040^{\circ} \mathrm{C} / 6 \mathrm{~h}$ & air cooled & $1 \mathrm{~h}$ \\
$\mathrm{AC}-6$ & $1040^{\circ} \mathrm{C} / 6 \mathrm{~h}$ & air cooled & $6 \mathrm{~h}$ \\
\hline
\end{tabular}

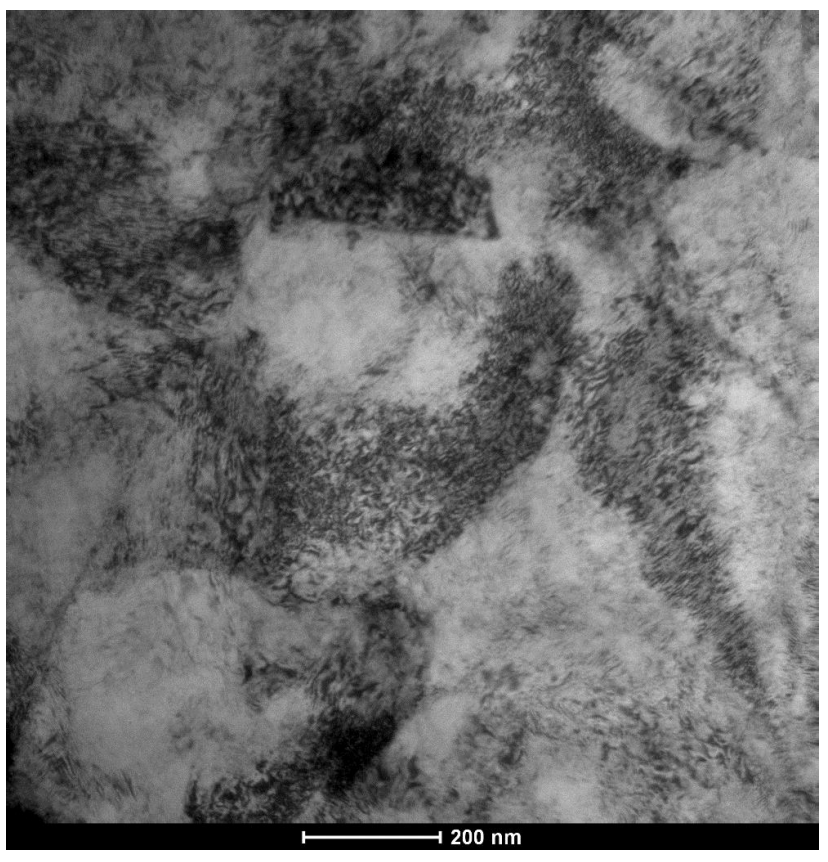

Figure 2: TEM image for 17-4PH as-received (air cooled condition). No evidence of precipitation can be seen, and grains contain a very high dislocation density, as indicated by the darker regions on the image.

TEM images from sample AC-1 are shown in Figure 3. These images are still dominated by dislocation contrast, but a few isolated precipitates are indicated at the higher magnification - these are the small, striped, circular regions in the image. It was originally postulated that these precipitates were carbides, due to their limited number and vicinity to grain boundaries. Composition could not be confirmed with the TEM measurements, but later atom probe tomography showed only precipitation of copper and no other element (see Section 5.3). Chemical analysis of these small precipitates with TEM would require much thinner samples. The black spots seen in the higher magnification image in Figure 3 may be small copper-rich precipitates. A TEM image from sample AC-6 is shown in Figure 4. The contrast from the high dislocation density continued to mask the ability to accurately image any precipitation present.

\subsection{D Atom Probe Tomography}

$3 \mathrm{D}$ atom probe tomography (APT) was conducted on an as-is sample as well as the AC-6 sample at Pacific 240 Northwest National Laboratory. Atom probe tomography analysis maps locations of specific atoms, and regions of visible clustering of atoms are indicative of clusters or precipitates. More specific details and information on this technique can be found in the literature, e.g. [32, 33]. 245 APT maps of $\mathrm{Cu}$ for the as-is sample are shown in Figure 5. Note that all the datasets shown were clipped to a thickness of $10 \mathrm{~nm}$ into the page for better clarity. The sample tip runs showed homogeneous $\mathrm{Cu}$ distribution, and one run (Figure 5(a)) captured several $\mathrm{Cu}$ precipitates. No other segregation was seen from the other atomic species. Concentration profiles, constructed from 5 at. $\% \mathrm{Cu}$ isoconcentration surfaces, showed enrichment of only $\mathrm{Cu}$ and no other species in the clusters. This difference in sample runs may be a further indication of inhomogeneity within and among samples in the air cooled state.

APT maps for the 17-4PH AC-6 sample in terms of $\mathrm{Cu}$, $\mathrm{Cr}$, and $\mathrm{Ni}$ atomic species are shown in Figure 6. These results show some clustering of $\mathrm{Cu}$, but no segregation or clustering of any other atomic species was seen. Concentration profiles for this sample AC-6, constructed from 5 at.\% $\mathrm{Cu}$ isoconcentration surfaces, again showed enrichment of only $\mathrm{Cu}$ and no other species in the clusters. Copper appears to be in the early stages of nucleation, clusters are measured to be less than $1 \mathrm{~nm}$ in diameter, and statistically significant clustering is difficult to discern. This supports the previous results where precipitation was not visible in TEM images for sample AC-6. Since $\mathrm{Cu}$ is in such an early stage of nucleation, it is difficult to distinguish the precipitates and provide an accurate estimate of number density. Nevertheless, cluster number densities were estimated from two runs as $3.2 \times 10^{24}$ clusters $/ \mathrm{m}^{3}$ and $6.47 \times 10^{23}$ clusters $/ \mathrm{m}^{3}$. The difference between these two estimates on the same sample is likely due to the illdefined nature of the clusters and/or inhomogeneity within the sample, which could be due to the variation in nucleation sites within this material with such a high density of dislocations. 


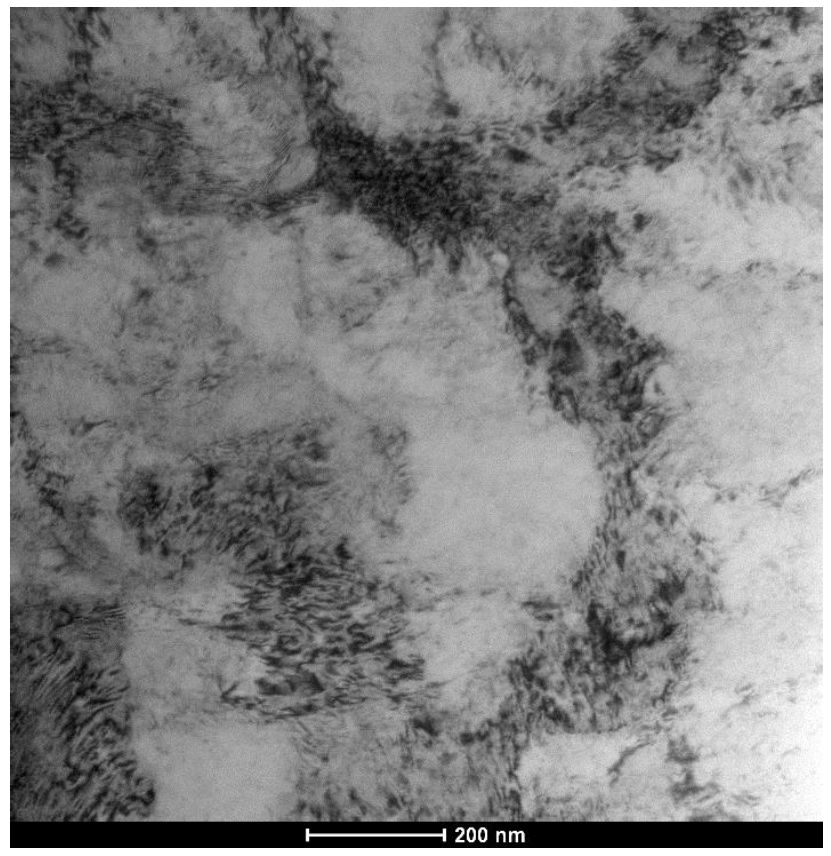

(a)

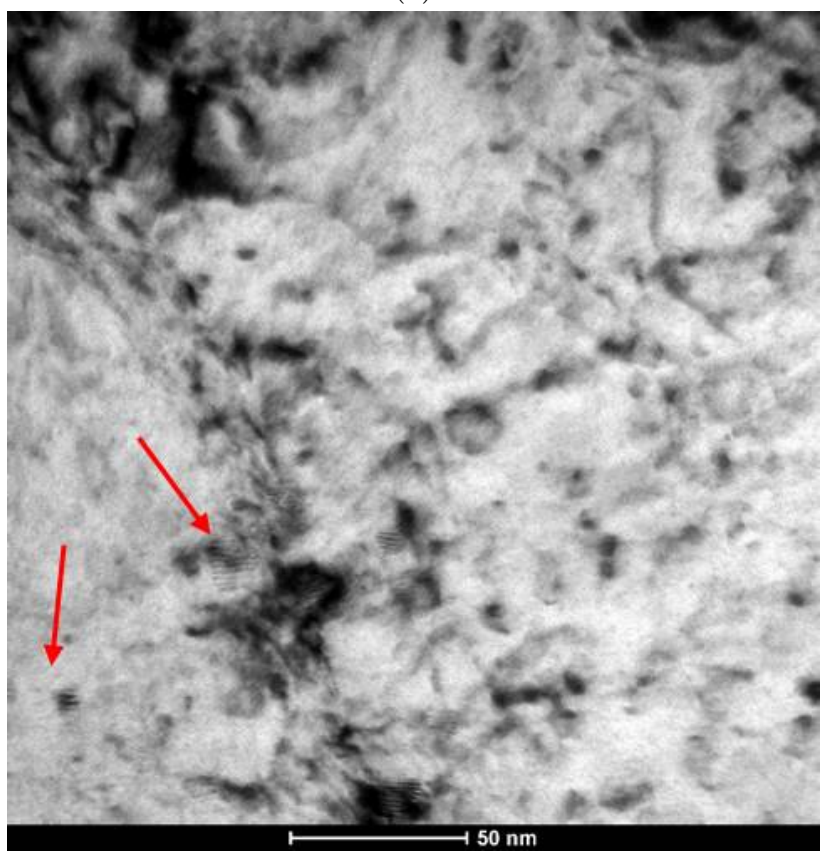

(b)

Figure 3: TEM images for $17-4 \mathrm{PH}$ sample aged at $400^{\circ} \mathrm{C}$ for 1 hour (AC-1). Arrows indicate some isolated precipitates in image (b).

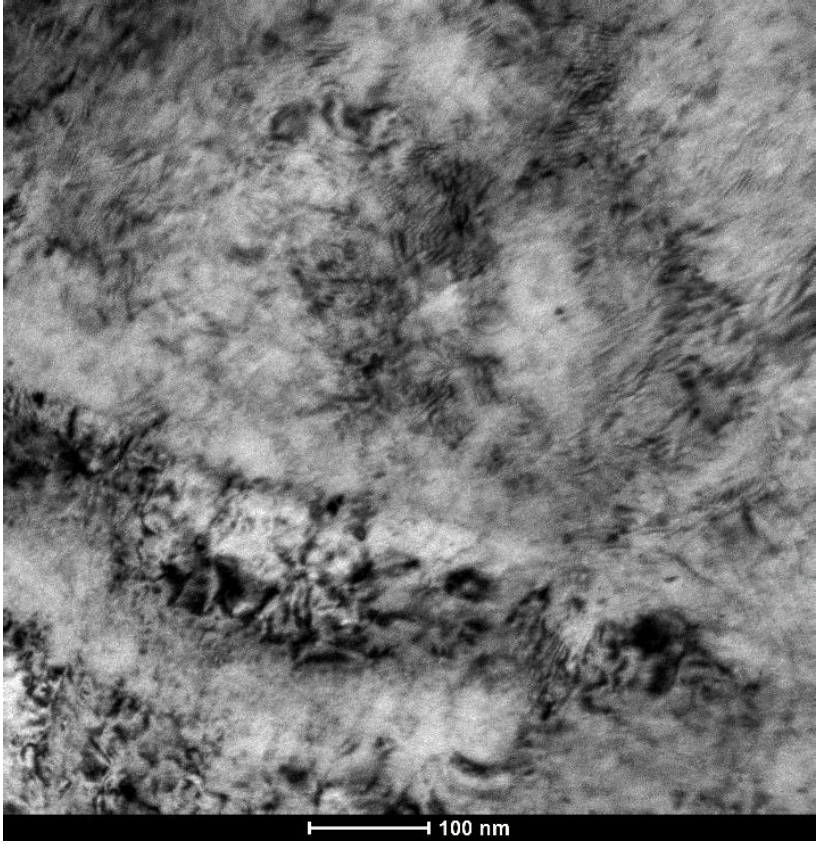

Figure 4: TEM image for $17-4 \mathrm{PH}$ sample aged at $400^{\circ} \mathrm{C}$ for 6 hours (AC-6). The contrast indicates there is still a high density of dislocations, which is likely masking the ability to image the precipitates.

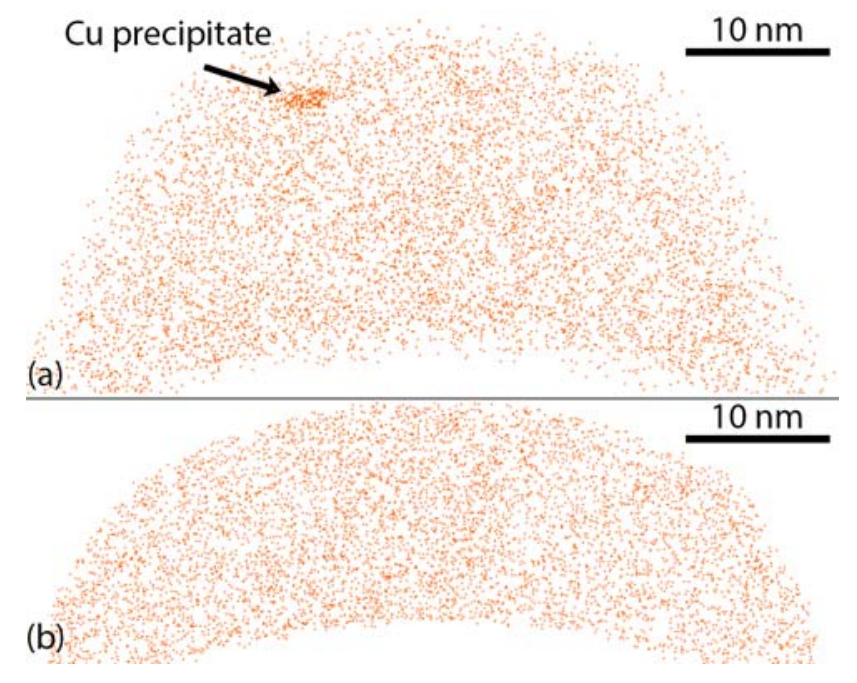

Figure 5: APT atom maps of $\mathrm{Cu}$ for two runs from sample $17-4 \mathrm{PH}$ AC. 


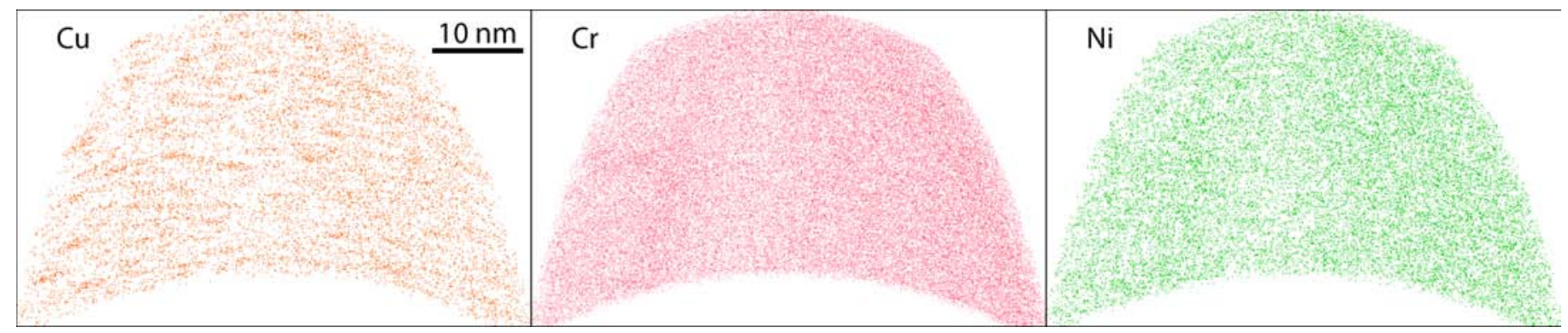

Figure 6: APT atom maps of $\mathrm{Cu}, \mathrm{Cr}$, and $\mathrm{Ni}$ (from left to right image) from sample 17-4PH AC-6.

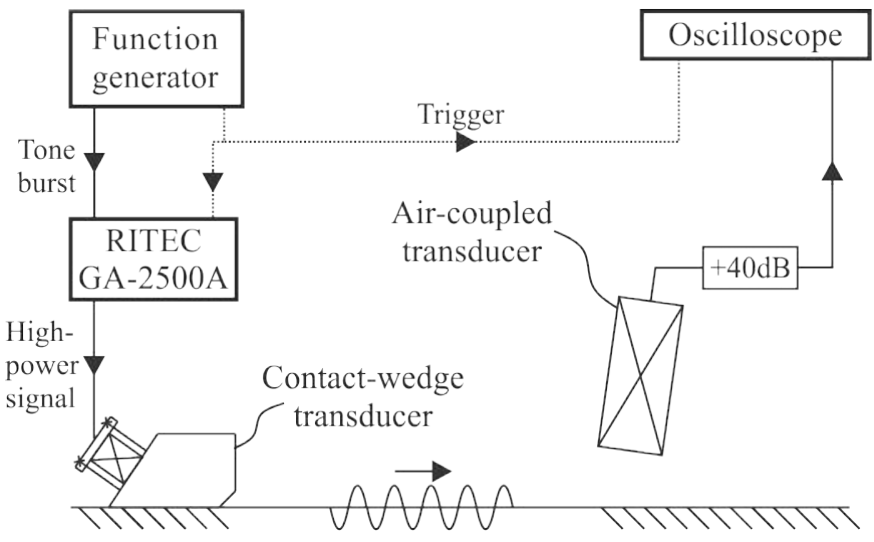

Figure 7: Experimental setup for Rayleigh surface wave measurements using an air-coupled transducer [34].

\section{Nonlinear Ultrasonic Measurements}

\subsection{Rayleigh Wave Measurements}

The experimental setup for the surface measurements is shown in Figure 7. A $2.1 \mathrm{MHz}$ tone burst was generated ${ }_{305}$ by a function generator and amplified by a RITEC amplifier. A narrow band piezoelectric transducer was used to excite a longitudinal wave into an acrylic wedge. This ge is designed to generate a Rayleigh surface wave in the sample. An air-coupled transducer with a center frequency of $3.9 \mathrm{MHz}$ was used to receive the longitudinal wave that was leaked by the Rayleigh wave into air. The acrylic wedge was clamped to a specimen and separated the air-coupled transducer by a specific distance. The signal was obtained at multiple propagation distances to obtain one measurement set. Three measurement sets were obtained for each sample and the wedge was removed, cleaned and oiled in between each set. More details on

\subsection{Data Processing}

A Hann window was applied to the signal to remove the ${ }_{32}$ effects of the ringing of the transducer, and the FFT was calculated from the windowed signal. The amplitudes of the first and second harmonic wave were determined in this manner for each of the propagation distances. An example of the measured amplitude ratio $A_{2} / A_{1}^{2}$ over propagation distance is shown in Figure 8.

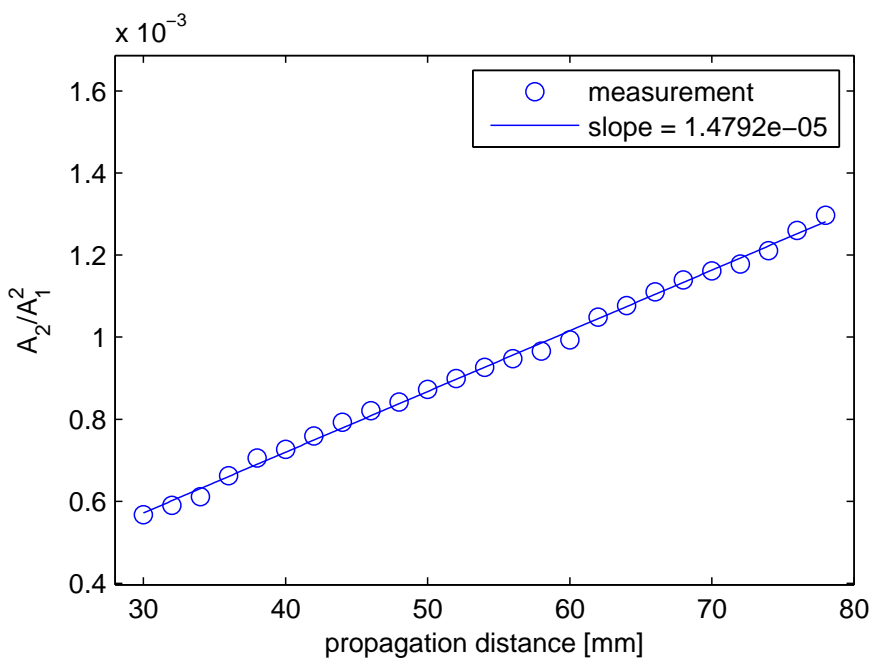

Figure 8: Example measurement of amplitude ratio over propagation distance, where the slope of the linear fit corresponds to $\beta^{\prime}$.

Linear regression was then performed between $A_{2} / A_{1}^{2}$ and $x$. The slope of the linear fit is directly proportional to the acoustic nonlinearity parameter and is denoted by $\beta^{\prime}$. The values of the three measurements for each sample in each condition were then averaged, and error bars on the measurement results represent one standard deviation from the mean value.

\section{Nonlinear Ultrasonic Measurement Results}

Results for normalized measured $\beta^{\prime}$ over heat treatment conditions with Rayleigh waves and an air-coupled detection system are shown in Figure 9 [31]. Results show about a $10 \%$ difference between air cooled as-is samples, and a decrease in $\beta$ with increasing heat treatment time at $400^{\circ} \mathrm{C}$, with a maximum decrease of $47 \%$ for the maximum aging time of 6 hours. Note that the difference in measured $\beta^{\prime}$ for the as-is samples is not insignificant, but it is small compared to the change in $\beta^{\prime}$ detected during thermal aging. A summary of the measured changes in $\beta^{\prime}$ with Rayleigh waves for thermally aged samples is given in Table 3. 
Table 3: Normalized measured $\beta^{\prime}$ for water quenched and air cooled samples, using Rayleigh waves. Note $\beta_{a s-i s}^{\prime}$ refers to the air cooled or water quenched state.

\begin{tabular}{cc}
\hline Sample Condition & Rayleigh $\Delta \beta^{\prime} / \beta_{a s-i s}^{\prime}$ \\
\hline \hline WQ & 0 \\
WQ-1 & $-19 \%$ \\
AC & $0 \%$ \\
AC- 0.1 & $-8 \%$ \\
AC-1 & $-34 \%$ \\
AC- 6 & $-47 \%$ \\
\hline
\end{tabular}

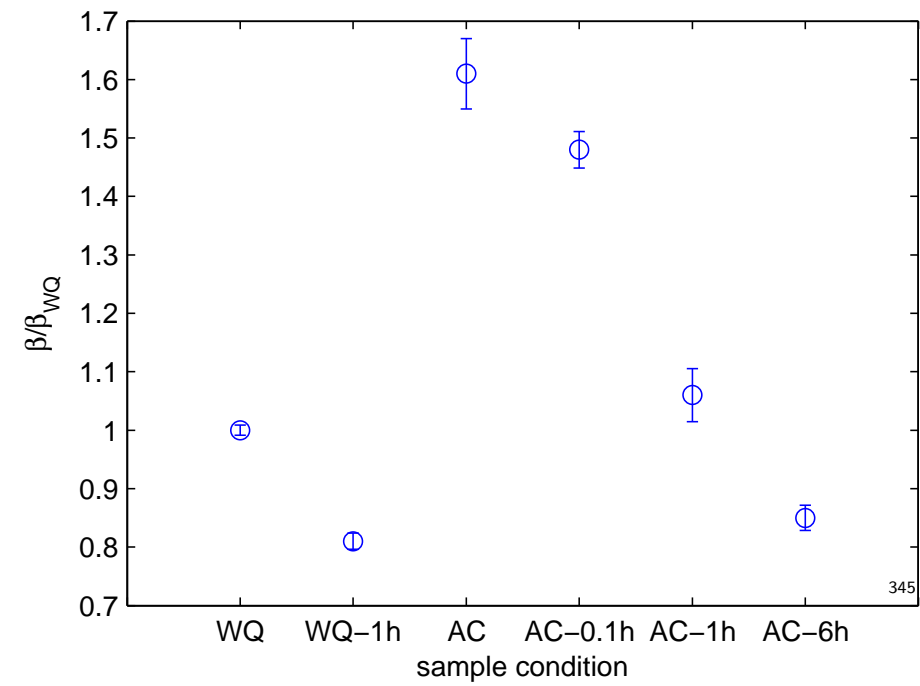

Figure 9: Normalized measured $\beta^{\prime}$ with Rayleigh waves and aircoupled detection for $17-4 \mathrm{PH}$ thermally aged material at $400^{\circ} \mathrm{C}$.

Each data point represents an average over three separate measure-350 ments.

\section{Discussions}

The thermal aging schedule utilized to induce copper precipitation in $17-4 \mathrm{PH}$ was successful in terms of the induced increase in hardness and TEP values. However TEM and APT analyses showed that precipitation was in earlier stages of nucleation than indicated in previous work . According to Mirzadeh et al. [30], aging at $480^{\circ} \mathrm{C}$ for 1 hour (i.e. as in experiments in [13]) results in a similar increase in hardness as aging for more than 100 hours at $400^{\circ} \mathrm{C}$. Our samples should therefore be in an earlier stage of hardening than the one of Hsaio et al. [13]. The smaller ameter), compared to TEM measurements of precipitate size in Hsaio et al. [13] (15-25 nm in diameter), supports this. It should be pointed out however that the chemical composition of the $17-4 \mathrm{PH}$ material used in [13] was not identical to the 17-4PH material used in this work, which limits the applicability of such a comparison.

Measurements of $\beta^{\prime}$ using Rayleigh waves showed a decrease in $\beta^{\prime}$ with increasing aging time, showing these measurements are able to detect changes in the $17-4 \mathrm{PH}$ microstructure during thermal aging. The measured decrease in $\beta^{\prime}$ with heat treatment time is likely due to the increased formation of copper precipitates that form in increasing quantities up to peak aging time, which was evident in the APT analysis as well as indirectly in the hardness and TEP results. The precipitate-pinned dislocation model [15] predicts that:

$$
\Delta \beta \propto \Lambda r^{3} / N^{1 / 3}
$$

where $\Lambda$ is the dislocation density, $r$ is the average radius of the precipitates and $N$ the number density of precipitates.

It is interesting to point out that the measurement variation in the air cooled compared to water-quenched samples is consistent with previous results [35], where the authors measured the variation of $\beta^{\prime}$ measurements for different cooling times. Faster cooling times correlated with a smaller measurement variation.

The following discussions focus on how the Rayleigh measurements can be used to extract precipitate parameters in this aged material, and the implications of these results on radiation damage detection.

\subsection{Expected Trends with Nonlinearity}

In the early stages of precipitate hardening, strengthening is related to the stress required for dislocations to cut through small coherent precipitates. After precipitates grow beyond a critical radius, $r_{c}$, strengthening is associated with dislocations bowing around precipitates, i.e. the Orowan mechanism. A model for strengthening due to small coherent precipitates has been previously applied to precipitate hardening mechanisms in precipitatehardenable material $[36,30]$ :

$$
\Delta \tau \propto f^{1 / 2} r^{1 / 2}
$$

where $\tau$ is the flow stress, $f$ is the volume fraction of precipitates and $r$ is the precipitate radius. The change in hardness is assumed to be proportional to the increase in yield stress due to precipitate strengthening, so the relation of hardness to precipitate parameters has been shown $[36,30]$ to be:

$$
\Delta \tau \propto \Delta H_{v} \propto N^{1 / 2} r^{2}
$$


where $N$ is the number density of precipitates, and $H_{v}$ is the Vickers hardness. This assumes precipitates are spherical, such that $f=N(4 \pi / 3) r^{3}$. Considering the theory for precipitate-pinned dislocation contribution to nonlinearity as described by Equation 3, the expected relation of $\beta$ to changes in hardness due to precipitation is

$$
\Delta \beta \propto \frac{r^{13 / 3}}{H_{v}^{2 / 3}}
$$

If the radius of precipitates is constant over increasing heat treatment time, then the change in acoustic nonlinearity parameter can be related to increasing hardness by:

$$
\Delta \beta \propto \frac{1}{H_{v}^{2 / 3}}
$$

\subsection{Interpretation of Rayleigh wave results}

The results of measured $\beta$ with Rayleigh waves is plotted against the hardness data in Figure 10. If we assume the radius of the precipitates is roughly constant over heat treatment times from 0-6 hours, then the measured $\beta^{\prime}$ should be linearly proportional to $1 / H_{v}^{2 / 3}$. Further, the slope of the resulting linear fit between $\beta$ and $1 / H_{v}^{2 / 3}$ should be proportional to $r^{13 / 3}$. That the relation between $\beta$ and $1 / H_{v}^{2 / 3}$ for the air cooled bar samples is 400 in fact linear supports the assumption that the radius is roughly constant over heat treatment time. So, the relative change in radius of the precipitates between the air cooled and water quenched states can be estimated by comparing the slopes of the linear fit between $\beta$ and $1 / H_{v}^{2 / 3}$. Using ${ }_{405}$ this method, it is estimated that the precipitates in the 17-4PH air cooled samples are about $30 \%$ larger in radius than precipitates in the $17-4 \mathrm{PH}$ water quenched samples. A larger radius of precipitates in the air cooled state is consistent with the higher measured $\beta$ in this as-is sample compared to the water-quenched sample.

Note that this is an extremely rough estimation $\operatorname{and}_{410}$ it is based off a linear fit from only two points available for the water-quenched specimen. Clearly more data is necessary to clarify, with any certainty, the relationship between $\beta$, hardness, and the radius of the precipitates present in the thermally aged microstructure. Neverthe- ${ }_{415}$ less, this model and method could be used to extract precipitate information if assumptions and estimations are validated by microstructural characterizations.

\subsection{Implications on Radiation Damage Detection}

420

Previous work has shown that longitudinal wave measurements of $\beta^{\prime}$ over the same propagation distance can detect changes in irradiated RPV steels, where the dominant microstructural feature that evolves are the copper-rich precipitates $[1,2]$. These previous measurements were con-425 ducted on JRQ material (ASTM A533B class 1), which is a reference RPV steel material, that was neutron irradiated at two different irradiation temperatures of $255^{\circ} \mathrm{C}$ and $290^{\circ} \mathrm{C}$. While the number density of precipitates formed

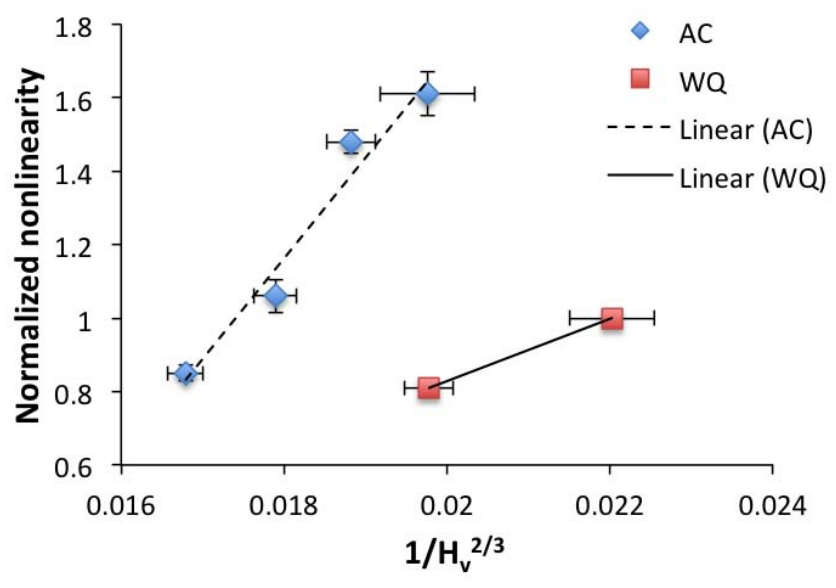

Figure 10: Normalized measured $\beta^{\prime}$ with Rayleigh waves plotted against $1 / H_{v}^{2 / 3}$, after Equation 6 .

over the thermal aging times applied to the $17-4 \mathrm{PH}$ material are roughly of the same order of magnitude as the number density of precipitates formed during radiation damage of RPV steel interrogated in previous work with longitudinal wave $\beta^{\prime}$ measurements $[1,2]$, the dislocation density of $17-4 \mathrm{PH}$ is about an order of magnitude greater than in the JRQ material. The microstructural parameters and measured changes in $\beta^{\prime}$ for $17-4 \mathrm{PH}$ compared with the neutron irradiated JRQ sample sets are summarized in Table 4.

Note that this comparison is further complicated by the fact that the Rayleigh wave measurements of $\beta^{\prime}$ on $17-4 \mathrm{PH}$ utilized a much longer wave propagation distance than the longitudinal measurements of $\beta^{\prime}$ on neutron irradiated JRQ material.

\section{Conclusions}

This paper investigated surrogate sample sets of 17 $4 \mathrm{PH}$ stainless steel material, which is known to produce copper precipitates during thermal aging. These results can be used to investigate the effects of the copper precipitates on measured $\beta^{\prime}$ for neutron irradiated steel, with the eventual goal to deconvolve different microstructural effects of irradiated steel microstructure on $\beta^{\prime}$. Investigations into 17-4PH stainless steel material showed successful heat treatments of samples designed for nonlinear Rayleigh wave measurements. Hardness and TEP measurements provided indirect evidence of increasing amounts of precipitation induced during increasing times of thermal aging at $400^{\circ} \mathrm{C}$, while TEM and APT showed direct evidence of the high dislocation density and early nucleation stages of precipitation. Rayleigh wave measurements of $\beta^{\prime}$ decreased with increasing heat treatment time of $17-4 \mathrm{PH}$ stainless steel, which is consistent with the precipitate-pinned dislocation contribution to $\beta^{\prime}$. Unfortunately these specific results cannot be directly compared to $\beta^{\prime}$ measurements on irradiated steel due to an order of magnitude larger dislocation density and smaller precipitate size. A model 
Table 4: Comparison of precipitate parameters and $\beta$ measurements in 17-4PH surrogate material and neutron irradiated RPV steel.

\begin{tabular}{cccccc}
\hline Material & $\begin{array}{c}\text { Damage } \\
\text { type }\end{array}$ & $\begin{array}{c}\text { Estimated dislocation } \\
\text { density }\left(10^{15} \mathrm{~m}^{-2}\right)\end{array}$ & $\begin{array}{c}N \text { range } \\
\left(10^{23} \mathrm{~m}^{-3}\right)\end{array}$ & $\begin{array}{c}r \text { range } \\
(\mathrm{nm})\end{array}$ & $\begin{array}{c}\beta^{\prime} / \beta_{0}^{\prime} \\
\text { range }\end{array}$ \\
\hline \hline 17-4PH & Thermal Aging & $4[9]$ & $6-3$ & 0.5 & -8 to $-47 \%$ \\
JRQ (255C) & Neutron Radiation & $0.1-0.2[37]$ & $8-12[38]$ & $1.0[38]$ & 65 to $97 \%[1]$ \\
JRQ (290C) & Neutron Radiation & $0.1-0.2[37]$ & $1-3[39]$ & $1.0[39]$ & 5 to $18 \%[2]$ \\
\hline
\end{tabular}

430

ing hardness to number density and radius of precipitates is used to estimate differences in precipitate radius due to different initial cooling rates following solution annealing.

\section{Acknowledgements}

A portion of this research was performed using EMSL, a DOE Office of Science User Facility sponsored by the Office of Biological and Environmental Research and located at Pacific Northwest National Laboratory. The au-490 thors would like to thank Dan Edwards and Alicia Certain at Pacific Northwest National Laboratory for their help with the TEM and APT measurements and interpretations. This work was supported by funding received ${ }_{495}$ from the DOE Office of Nuclear Energy's Nuclear Energy University Programs (NEUP).

\section{References}

[1] K. H. Matlack, J. J. Wall, J.-Y. Kim, J. Qu, L. J. Jacobs, H.-W. Viehrig, Evaluation of radiation damage using nonlinear ultrasound, Journal of Applied Physics 111 (5) (2012) 054911. doi:10.1063/1.3692086.

[2] K. H. Matlack, J.-Y. Kim, J. J. Wall, J. Qu, L. J. Jacobs, M. A. Sokolov, Sensitivity of ultrasonic nonlinearity to irradiated, annealed, and re-irradiated microstructure changes in RPV steels, Journal of Nuclear Materials 448 (2014) 26-32.

[3] M. Miller, B. D. Wirth, G. Odette, Precipitation in neutronirradiated $\mathrm{Fe}-\mathrm{Cu}$ and $\mathrm{Fe}-\mathrm{Cu}-\mathrm{Mn}$ model alloys : a comparison of APT and SANS data, Materials Science and Engineering A 353 (2003) 133-139.

[4] N. Castin, L. Malerba, G. Bonny, M. Pascuet, M. Hou, Modelling radiation-induced phase changes in binary $\mathrm{FeCu}$ and ternary $\mathrm{FeCuNi}$ alloys using an artificial intelligence-based atomistic kinetic Monte Carlo approach, Nuclear Instruments and Methods in Physics Research Section B: Beam Interactions with Materials and Atoms 267 (18) (2009) 3002-3008. doi:10.1016/j.nimb.2009.06.092.

[5] G. Worrall, J. Buswell, C. English, M. Hetherington, G. Smith, A study of the precipitation of copper particles in a ferrite matrix, Journal of Nuclear Materials 148 (1) (1987) 107-114. doi:10.1016/0022-3115(87)90525-3.

[6] G. Dobmann, L. Debarberis, J.-F. Coste, Aging material evalu- ${ }^{525}$ ation and studies by non-destructive techniques (AMES-NDT) - a European network project, Nuclear Engineering and Design 206 (2001) 363-374.

[7] Q. Yu, G. S. Was, L. M. Wang, G. Odette, D. E. Alexander, Hardening and microstructure of model reactor pressure vessl steel alloys using proton irradiation, Materials Research Society Symposium Proceedings 650 (2001) R6.2.1-R.6.2.6.
[8] G. Odette, G. Lucas, D. Klingensmith, Anomalous hardening in model alloys and steels thermally aged at 290C and 350C: implications to low flux irradiation embrittlement, in: R. Nanstad, M. Hamilton, F. Garner, A. Kumar (Eds.), 18th International Symposium on the Effects of Radiation on Materials, ASTM STP-1325, ASTM International, West Conshohocken, PA, 1999, pp. 88-101.

[9] F. Christien, M. Telling, K. Knight, Neutron diffraction in situ monitoring of the dislocation density during martensitic transformation in a stainless steel, Scripta Materialia 68 (7) (2013) 506-509. doi:10.1016/j.scriptamat.2012.11.031.

[10] D. Bhattacharya, T. Jayakumar, V. Moorthy, S. Vaidyanathan, B. Raj, Characterization of microstructures in 17-4-PH stainless steel by magnetic Barkhausen noise analysis, NDT \& E International 26 (3) (1993) 141-148. doi:10.1016/0963-8695(93)90600Y.

[11] M. Murayama, Y. Katayama, K. Hono, Microstructural Evolution in a 17-4 PH Stainless Steel after Aging at 400C, Metallurgical and Materials Transactions A 30A (1999) 345-353.

[12] U. K. Viswanathan, P. K. K. Nayar, R. Krishnan, Kinetics of precipitation in 17-4 PH stainless steel, Materials Science and Technology 5 (April) (1989) 346-349.

[13] C. N. Hsiao, C. S. Chiou, J. R. Yang, Aging reactions in a 17$4 \mathrm{PH}$ stainless steel, Materials Chemistry and Physics 74 (2) (2002) 134-142. doi:10.1016/S0254-0584(01)00460-6.

[14] G. Odette, G. E. Lucas, D. Klingensmith, On the Effect of Neutron Flux and Composition on Hardening of Reactor Pressure Vessel Steels and Model Alloys, in: Materials Research Society Symposium Proceedings, Vol. 650, 2001, pp. R6.4.1-R6.4.6.

[15] J. H. Cantrell, W. T. Yost, Determination of precipitate nucleation and growth rates from ultrasonic harmonic generation, Applied Physics Letters 77 (13) (2000) 1952-1954.

[16] J. H. Cantrell, W. T. Yost, Nonlinear ultrasonic characterization of fatigue microstructures, International Journal of Fatigue 23 (2001) S487-S490.

[17] J. H. Cantrell, Nonlinear dislocation dynamics at ultrasonic frequencies, Journal of Applied Physics 105 (043520) (2009) 1-7. doi:10.1063/1.3081972.

[18] J. Herrmann, J.-Y. Kim, L. J. Jacobs, J. Qu, J. W. Littles, M. F. Savage, Assessment of material damage in a nickel-base superalloy using nonlinear Rayleigh surface waves, Journal of Applied Physics 99 (2006) 124913. doi:10.1063/1.2204807.

[19] S. V. Walker, J.-Y. Kim, J. Qu, L. J. Jacobs, Fatigue damage evaluation in A36 steel using nonlinear Rayleigh surface waves, NDT \& E International 48 (2012) 10-15. doi:10.1016/j.ndteint.2012.02.002.

[20] V. V. S. J. Rao, E. Kannan, R. V. Prakash, K. Balasubramaniam, Fatigue damage characterization using surface acoustic wave nonlinearity in aluminum alloy AA7175-T7351, Journal of Applied Physics 104 (12) (2008) 123508. doi:10.1063/1.2956396.

[21] D. C. Hurley, D. Balzar, P. T. Purtscher, Nonlinear ultrasonic assessment of precipitation hardening in ASTM A710 steel, Journal of Materials Research 15 (9) (2000) 2036-2042.

[22] D. J. Barnard, G. E. Dace, O. Buck, Acoustic harmonic generation due to thermal embrittlement of Inconel 718, Journal of Nondestructive Evaluation 16 (2) (1997) 67-75. doi:10.1023/a:1022616400990. 
23] Y. Li, S. Hu, C. H. Henager, H. Deng, F. Gao, X. Sun, M. A Khaleel, Computer simulations of interstitial loop growth kinetics in irradiated bcc Fe, Journal of Nuclear Materials 427 (1-3) (2012) 259-267. doi:10.1016/j.jnucmat.2012.05.004.

[24] A. Ruiz, N. Ortiz, A. Medina, J.-Y. Kim, L. J. Jacobs, Application of ultrasonic methods for early detection of thermal damage in 2205 duplex stainless steel, NDT \& E International 54 (2013) 19-26. doi:10.1016/j.ndteint.2012.11.009.

[25] A. Viswanath, B. P. C. Rao, S. Mahadevan, T. Jayakumar, R. Baldev, Microstructural characterization of M250 grade maraging steel using nonlinear ultrasonic technique, Journal of Materials Science 45 (24) (2010) 6719-6726.

[26] S. Baby, B. N. Kowmudi, C. M. Omprakash, D. V. V. Satyanarayana, K. Balasubramaniam, V. Kumar, Creep damage assessment in titanium alloy using a nonlinear ultrasonic technique, Scripta Materialia 59 (2008) 818-821. doi:10.1016/j.scriptamat.2008.06.028.

[27] K. Balasubramaniam, J. S. Valluri, R. V. Prakash, Creep damage characterization using a low amplitude nonlinear ultrasonic technique, Materials Characterization 62 (3) (2011) 275-286. doi:10.1016/j.matchar.2010.11.007.

[28] K. H. Matlack, J. J. Wall, J.-Y. Kim, J. Qu, L. J. Jacobs, Nonlinear Ultrasound to Monitor Radiation Damage in Structural Steel, in: 6th European Workshop on Structural Health Monitoring, 2012, pp. 1-8.

[29] A. Hikata, B. B. Chick, C. Elbaum, Dislocation contribution to the second harmonic generation of ultrasonic waves, Journal of Applied Physics 36 (1) (1965) 229-236.

[30] H. Mirzadeh, a. Najafizadeh, Aging kinetics of 17-4 PH stainless steel, Materials Chemistry and Physics 116 (1) (2009) 119-124. doi:10.1016/j.matchemphys.2009.02.049.

[31] S. Thiele, Air-coupled detection of Rayleigh surface waves to asses material nonlinearity due to precipitation in alloy steel, Master's thesis, Georgia Institute of Technology (2013).

[32] M. Miller, P. Pareige, M. G. Burke, Understanding Pressure Vessel Steels: An Atom Probe Perspective, Materials Characterization 44 (2000) 235-254.

[33] M. Miller, K. Russell, Embrittlement of RPV steels: An atom probe tomography perspective, Journal of Nuclear Materials 371 (1-3) (2007) 145-160. doi:10.1016/j.jnucmat.2007.05.003.

[34] S. Thiele, J.-y. Kim, J. Qu, L. J. Jacobs, Air-Coupled Detection of Nonlinear Rayleigh Surface Waves to Assess Material Nonlinearity, Ultrasonicsdoi:10.1016/j.ultras.2014.04.020.

[35] A. Mukhopadhyay, R. Sarkar, S. Punnose, J. Valluri, T. K. Nandy, K. Balasubramaniam, Scatter in nonlinear ultrasonic measurements due to crystallographic orientation change induced anisotropy in harmonics generation, Journal of Applied Physics 111 (5) (2012) 054905. doi:10.1063/1.3686698.

[36] D. Ping, M. Ohnuma, Y. Hirakawa, Y. Kadoya, K. Hono, Microstructural evolution in $13 \mathrm{Cr} 8 \mathrm{Ni} 2.5 \mathrm{Mo} 2 \mathrm{Al}$ martensitic precipitation-hardened stainless steel, Materials Science and Engineering: A 394 (1-2) (2005) 285-295. doi:10.1016/j.msea.2004.12.002.

[37] J. Kocik, E. Keilova, J. Cizek, I. Prochazka, TEM and PAS study of neutron irradiated VVER-type RPV steels, Journal of Nuclear Materials 303 (2002) 52-64.

[38] A. Ulbricht, J. Bohmert, H.-W. Viehrig, Microstructural and Mechanical Characterization of Radiation Effects in Model Reactor Pressure Vessel Steels, Journal of ASTM International 2 (10) (2005) 1-14.

[39] R. K. Nanstad, M. Niffenegger, R. D. Kalkhof, M. Miller, M. A. Sokolov, P. Tipping, Fracture Toughness, ThermoElectric Power, and Atom Probe Investigations of JRQ Steel in I, IA, IAR, and IARA Conditions, Journal of ASTM International 2 (9) (2005) 1-17. 